\title{
Addition of Inhalation Training Devices and Smartphone Application to Verbal Counseling for Asthmatic Patients
}

\author{
Rania AA Mahmoud1, Sara M Tony2,3, Marian S Boshra1, Mona A Abdelrahman1, Haitham Saeed1, Hasnaa \\ Osama $^{3}$, Marwa 0 Elgendy ${ }^{4,5}$, Mohamed EA Abdelrahim ${ }^{1 *}$ \\ ${ }^{1}$ Clinical Pharmacy Department, Faculty of Pharmacy, Beni-Suef University, Beni-Suef, Egypt \\ ${ }^{2}$ Beni-Suef Specialized Hospital, Beni-Suef, Egypt \\ ${ }^{3}$ Technical Office of Deputy Minister of Health in Beni-Suif Directorate of Health Affairs, Beni-Suef, Egypt \\ ${ }^{4}$ Department of Clinical Pharmacy, Teaching Hospital of Faculty of Medicine, Faculty of Medicine, Beni-Suef University, \\ Beni-Suef, Egypt \\ ${ }^{5}$ Department of Clinical Pharmacy, Faculty of Pharmacy, Nahda University (NUB), Egypt \\ *Corresponding author: Mohamed EA Abdelrahim, Mohamedemam9@yahoo.com
}

Copyright: (C) 2022 Author(s). This is an open-access article distributed under the terms of the Creative Commons Attribution License (CC BY 4.0), permitting distribution and reproduction in any medium, provided the original work is cited.

\begin{abstract}
Background: One of the main issues with pressurized metered dose inhalers (pMDI) is that some patients find it difficult to use it properly. Methods: This study was carried out to compare the effect of traditional verbal counseling and that of adding an inhalation training device, such as Flo-Tone or Clip-Tone, along with a smartphone application on the incidence of inhalation technique mistakes and the pulmonary function of asthmatic adults and children. Results: The lung function of those in the advanced counseling group significantly improved on the second visit $(p<0.001)$, whereas for those in the verbal counseling group, their lung function only improved on the third visit $(p<0.001)$. For both the groups, the mean number of mistakes in regard to the steps in inhalation technique decreased significantly $(p<0.001)$, with an overall higher percentage in the advanced counseling group. Conclusion: The use of training devices and smartphone applications in addition to traditional verbal counseling for teaching asthmatic adults and children the correct inhalation technique steps using pMDI resulted in a significant improvement in pulmonary function and a significant reduction in the number of inhalation technique mistakes, compared to traditional verbal counseling alone.
\end{abstract}

Keywords: Flo-Tone; Clip-Tone; Counseling; Asthma in adults and children; Inhalation technique; MDI, FEV 1 ; PEF; Smartphone application

Online publication: February 18, 2022

\section{Background}

One of the main issues with pressurized metered dose inhalers (pMDI) is that some patients find it difficult to use pMDI properly. Poor pMDI inhalation techniques, especially inhalation at an incorrect inspiratory flow, may lead to sub-therapeutic effects due to poor lung deposition ${ }^{[1-3]}$. In previous studies, such inhalation technique has been noted even with continuous verbal counseling ${ }^{[1-3]}$. This study was designed to compare the effect of traditional verbal counseling and that of adding a training device that signals correct inspiratory flow, such as Flo-Tone or Clip-Tone (Clement Clarke International, United Kingdom) as well 
as a smartphone application (Clin-e-cal Limited, UK) that can detect the specific whistle frequency. The pulmonary function and incidence of mistakes in the inhalation technique of asthmatic adults and children were measured.

\section{Methods}

This study was conducted in the chest clinic at Beni-Suef University Hospital, the school's health insurance clinic, and Beni-Suef Chest Hospital in Beni-Suef, Egypt upon approval by the Research Ethics Committee of the Faculty of Pharmacy, Beni-Suef University (REC-H-Ph-BSU-18001) as well as following the Declaration of Helsinki. Written informed consents were obtained from the participants. A total of 400 asthmatic patients were recruited in this study. The patients were divided into two study groups. The first study group consisted of 200 asthmatic children who were divided into two groups: a verbal counseling group $(n=100)$ and an advanced counseling group $(n=100)$. The advanced counseling group utilized the Flo-Tone attached to the pMDI plus the Trainhaler smartphone application in addition to verbal counseling. The second group consisted of 200 asthmatic adults who were also divided into two groups: a verbal counseling group $(n=100)$ and an advanced counseling group $(n=100)$. The advanced counseling group utilized the Clip-Tone attached to the pMDI plus the Clip-Tone Buddy smartphone application in addition to traditional verbal counseling. In short, the participants in the first and second group received either verbal or advanced counseling by the training devices and smartphone application.

All recruited subjects had three consecutive visits one month apart. At each visit, their pulmonary functions [peak expiratory flow rate $(\mathrm{PEF})$ and forced expiratory volume in one second represented as percentage of the predicted value $\left.\left(\mathrm{FEV}_{1} \%\right)\right]$ were measured three times using a spirometer (One Flow, Clement Clarke International), and the highest reading was recorded. According to the ERS/ISAM task force consensus, the pMDI inhalation technique can be separated into several steps. It has been revealed that this separation of steps may help subjects improve their inhalation technique as it makes pMDI counseling more operative and allows one to take note of the challenging steps ${ }^{[4]}$. At each visit, the participants' inhalation techniques were assessed. Verbal inhalation technique was performed, and the number of inhalation technique mistakes were recorded, and then corrected. In both the advanced counseling groups, the subjects were instructed to inhale from the training device attached to the pMDI until they hear a whistling sound and to maintain the sound for five seconds. The duration of inhalation, represented by the duration of the whistling sound, was measured and recorded using the smartphone application. In the second group, the scores obtained from the Asthma Control Test (ACT) (determination of asthma control) were recorded.

\section{Statistical analysis}

In each study, an analysis of the outcomes was performed using the student t-test for between-group and within-group comparisons. A repeated measure analysis of variance test with least significant difference correction was used to compare the effect of the intervention throughout the three visits and between groups. Chi-square test was used for analyzing the achievement of each correct step between both groups (SPSS 23.0, Chicago, USA).

\section{Results}

In the first study group, with children using pMDI, the lung function of the advanced counseling group (PEF and $\mathrm{FEV}_{1} \%$ predicted) improved significantly on the second visit, whereas the lung function of the verbal counseling group improved only on the third visit $(p<0.05)$. The total mean number of mistakes of both groups decreased significantly $(p<0.05)$ after the first and second visits. Also, there was a significant decrease in the number of mistakes $(p<0.01)$ on each visit compared to the previous visit, especially in the 
advanced counseling group. Moreover, for the advanced counseling group, the inhalation duration measured by the smartphone application increased significantly $(p<0.05)$ on the second and third visits. In the second study group, with adults using pMDI, the lung function of the advanced counseling group significantly improved $(p<0.001)$ on the second visit, whereas for the verbal counseling group, their lung function only improved on the third visit $(p<0.001)$. In addition to that, more patients in the advanced counseling group had $\geq 3$-point monthly increases in terms of their ACT score in comparison to the verbal counseling group. The mean number of mistakes of both groups in regard to inhalation technique steps decreased significantly $(p<0.001)$, with an overall higher percentage in the advanced counseling group.

\section{Discussion}

The use of a MDI training device with a smartphone application in addition to traditional verbal counseling decreases the incidence of errors in inhaler technique ${ }^{[3,5]}$. This combination significantly improves lung function and the total number of inhalation mistakes compared to traditional verbal counseling alone in asthmatic adults and children. This finding is crucial for obstructive lung disease patients since disease control is the main goal of asthma management. The incapability of asthmatics to use their MDIs appropriately, imitated by poor inhalation technique, has a huge influence on disease control ${ }^{[3]}$. It is estimated that up to $94 \%$ of such patients fail to use their MDIs correctly, compared to $84 \%$ of patients who fail to use dry powder inhalers correctly ${ }^{[6-14]}$. Earlier studies have shown the requirement of training and education to improve aerosol delivery from different inhalers ${ }^{[1-3,5-14]}$. Teaching patients to use MDI properly through verbal counseling has a significant influence on asthma control although a huge percentage of patients have failed to sustain the correct inhalation technique upon forgetting the training days after counseling ${ }^{[1-3,5,6]}$. Additionally, this study showed that a lower number of patients in the verbal counseling group improved in terms of their ACT score (expressed as the percentage of patients with $\geq 3$ ACT points increase) compared to the advanced counseling group. ACT was not included in the study group comprising of children as it was deemed difficult for most children recruited in this study.

\section{Conclusion}

The use of training devices and smartphone applications in addition to traditional verbal counseling for teaching asthmatic adults and children the correct pMDI inhalation technique steps resulted in a significant improvement of pulmonary function and a significant reduction in the number of inhalation technique mistakes, compared to traditional verbal counseling alone.

\section{Disclosure statement}

The authors declare no conflict of interest.

\section{Author contributions}

Mohamed EA Abdelrahim conceived and designed the study. All the authors were involved in administrative support, provision of study materials, collection and assembly of data, data analysis and interpretation, manuscript writing, as well as the final approval of the manuscript.

\section{References}

[1] Elgendy MO, Abdelrahim ME, Eldin RS, 2015, Potential Benefit of Repeated MDI Inhalation Technique Counselling for Patients with Asthma. Eur J Hosp Pharm, 22(6): 318-322. 
[2] Nicola M, Elberry A, Sayed O, et al., 2018, The Impact of Adding a Training Device to Familiar Counselling on Inhalation Technique and Pulmonary Function of Asthmatics. Advances in Therapy, 35(7): 1049-1058.

[3] Saeed H, Abdelrahim ME, Rabea H, et al., 2020, Impact of Advanced Patient Counseling Using a Training Device and Smartphone Application on Asthma Control. Respiratory Care, 65(3): 326-332.

[4] Laube BL, Janssens HM, de Jongh FHC, et al., 2011, What the Pulmonary Specialist Should Know About the New Inhalation Therapies. European Respiratory Journal, 37(6): 1308-1417.

[5] Tony SM, Abdelrahman MA, Osama H, et al., 2021, Advanced Counselling Using Training Device and Smartphone Application on Inhalation Technique from Metered-Dose Inhaler with Spacer Equipped with Different Interfaces in Asthmatic Children. International Journal of Clinical Practice, 75(9): e14413.

[6] Wael W, Sanders MJ, Hussein R, et al., 2021, The Effect of Clip-Tone ${ }^{\circledR}$ and Its Smartphone Application on Optimisation of Metered-Dose Inhalers Inhalation Technique. International Journal of Clinical Practice, 75(6): e14088.

[7] Harb HS, Ibrahim Laz N, Rabea H, et al., 2021, Real-Life Assessment of Chronic Obstructive Pulmonary Disease Patient Performance with Different Inhalers. International Journal of Clinical Practice, 75(4): e13905.

[8] Harb HS, Ibrahim Laz N, Rabea H, et al., 2021, Determinants of Incorrect Inhaler Technique in Chronic Obstructive Pulmonary Disease Patients. International Journal of Clinical Practice, 75(6): e14073.

[9] Harb HS, Ibrahim Laz N, Rabea H, et al., 2020, First-Time Handling of Different Inhalers by Chronic Obstructive Lung Disease Patients. Experimental Lung Research, 46(7): 258-269.

[10] Harb HS, Ibrahim Laz N, Rabea H, et al., Prevalence and Predictors of Suboptimal Peak Inspiratory Flow Rate in COPD Patients. European Journal of Pharmaceutical Sciences, 147: 105298.

[11] Saeed H, Salem HF, Rabea H, et al., 2019, Effect of Human Error, Inhalation Flow, and Inhalation Volume on Dose Delivery from Ellipta ${ }^{\circledR}$ Dry-Powder Inhaler. Journal of Pharmaceutical Innovation, 14(3): 239-244.

[12] Nicola M, Elberry AA, Sayed OM, et al., 2018, Effect of DPI's Training-Device on Inhalation Technique and Clinical Efficacy in Asthmatics. Beni-Suef University Journal of Basic and Applied Sciences, 7(2): 178-183.

[13] Elgendy MO, Abdelrahim ME, Eldin RS, 2015, Potential Benefit of Repeated Dry Powder Inhaler's Inhalation Technique Counseling on Asthmatic Patients. Pulmonary Therapy, 1(1): 91-101.

[14] Abdelrahim ME, 2010, Emitted Dose and Lung Deposition of Inhaled Terbutaline from Turbuhaler at Different Conditions. Respiratory medicine, 104(5): 682-689. 